\title{
Microwave-assisted Photocatalytic Degradation of Dimethyl Phthalate using a Microwave Discharged Electrodeless Lamp
}

\author{
Wenchao Liao and Peng Wang*
}

State Key Laboratory of Urban Water Resource and Environment, School of Municipal and Environmental Engineering, Harbin Institute of Technology, Harbin 150090, P.R. China

\begin{abstract}
O processo de fotodegradação catalítica assistido por radiação microondas do dimetilftalato foi investigado usando uma lâmpada de descarga sem eletrodos como fonte de radiação ultravioleta (UV). O dimetilftalato pode ser degradado rápida e completamente pelo processo. Os efeitos da dosagem fotocatalítica, intensidade de radiação UV, pH inicial e concentração de dimetilftalato, bem como o tempo de irradiação foram detalhamente estudados. Efeitos sinergéticos ocorreram entre a irradiação de microondas e a fotocatálise do $\mathrm{TiO}_{2}$, e a maior eficiência do processo pode ser associada aos efeitos não térmicos da irradiação de microondas. Dados experimentais evidenciaram que a irradiação por microondas pode causar significativa geração de radicais hidroxila. Os intermediários formados em maior concentração foram éster monometílico do ácido ftálico, ácido ftálico, o-fenil dietil cetona e anidrido o-ftálico. Com base nos dados experimentais, duas rotas de degradação inicial do dimetilftalato foram propostas.
\end{abstract}

The microwave-assisted photocatalytic degradation (MW/PC) of dimethyl phthalate (DMP) was investigated, using a microwave discharged electrodeless lamp (MDEL) as the UV source. DMP could be rapidly and completely degraded by the MW/PC process. The effects of photocatalyst dosage, UV light intensity, initial $\mathrm{pH}$ and concentration of DMP, as well as irradiation time, were studied in detail. Synergistic effects were found to exist between microwave irradiation and $\mathrm{TiO}_{2}$ photocatalysis, and the greater efficiency of the MW/PC process might be ascribed to nonthermal effects of microwave irradiation. Detection results confirmed that microwave irradiation could give rise to the generation of hydroxyl radicals. The major intermediates of DMP in the MW/PC process were deduced to be phthalic acid monomethyl ester, phthalic acid, $o$-phenyl diethyl ketone and $o$-phthalic anhydride. Based on the results, two initial degradation pathways of DMP were proposed.

Keywords: dimethyl phthalate, photocatalysis, microwave irradiation, microwave discharged electrodeless lamp

\section{Introduction}

Dimethyl phthalate (DMP) is one of the listed endocrine disrupters which may cause chromosome injuries in human leucocytes and interfere with the reproductive systems and normal development of animals and humans. ${ }^{1}$ DMP is widely used as plasticizers to improve the flexibility and durability of consumer products, food packaging materials and polyvinyl chloride (PVC) plastics. ${ }^{2}$ Furthermore, DMP is frequently identified in wastewater effluents and river water on account of its high mobility in the aquatic system. ${ }^{3}$ The most common method for the removal of DMP from wastewater is biological treatment, which is based on the

\footnotetext{
*e-mail: pwang73@vip.sina.com
}

metabolic degradation of DMP by microorganisms under aerobic or anaerobic conditions. ${ }^{4,5}$ However, several studies found that DMP were poorly degraded and considered recalcitrant to biological treatment. ${ }^{6}$

In recent years, a great deal of attention has been paid to the photocatalytic degradation of alkyl phthalate esters using titanium dioxide either immobilized on films or dispersed in aqueous suspensions. ${ }^{7,8}$ However, owing to the disadvantages of $\mathrm{TiO}_{2}$-based photocatalytic degradation, such as high recombination rate among electron/hole pairs, the quantum yield efficiency of photocatalytic process was relatively low and researches should be conducted to enhance the efficiency of photocatalytic processes.

In a previous research by our group, ${ }^{9-11}$ microwave irradiations have been found to be efficient for enhancing 
many kinds of advanced oxidation processes. Studies by Horikoshi et al. ${ }^{12,13}$ further demonstrated that microwave irradiation could considerably improve the photocatalytic efficiency of $\mathrm{TiO}_{2}$ for removal of pollutants, and a microwave discharged electrodeless lamp (MDEL) which could be directly lighted by microwaves was more effective in the microwave-assisted photocatalytic degradation of 2,4-dichlorophenoxyacetic acid than an electrode $\mathrm{Hg}$ lamp. ${ }^{14}$ Xiwang Zhang et al. ${ }^{15}$ also found that the coupled UV-Vis/microwave irradiation led to effective degradation of higher concentration dyes in $\mathrm{TiO}_{2} / \mathrm{MDEL}$ than in conventional photocatalysis.

The present work was aimed at studying the degradation of DMP in aqueous $\mathrm{TiO}_{2}$ dispersions under both UV and microwave irradiation using a MDEL. The factors influencing the degradation process, such as photocatalyst dosage, UV light intensity, initial pH of DMP, DMP concentration and irradiation time were investigated. Five different processes, including microwave-assisted photocatalysis (MW/PC), photocatalysis alone (PC), thermal-assisted photocatalysis (TH/PC), microwave alone (MW) and photolysis, were carried out to evaluate the synergistic effects between microwave irradiation and $\mathrm{TiO}_{2}$ photocatalysis. The efficiency of the degradation was assessed by DMP removal efficiency, formation of hydroxyl radicals and identification of intermediates.

\section{Experimental}

\section{Chemicals}

The DMP (analytical reagent grade) purchased from Tianjin Chemical Reagent Company of China was used as a model pollutant. Degussa P-25 $\mathrm{TiO}_{2}$ (specific surface area, $53 \mathrm{~m}^{2} \mathrm{~g}^{-1}$ by BET; particle size, $20-30 \mathrm{~nm}$ by TEM; composition, $83 \%$ anatase and $17 \%$ rutile by $\mathrm{X}$-ray diffraction) was used as a photocatalyst. $\mathrm{HCl}$ (analytical reagent grade, $0.1 \mathrm{~mol} \mathrm{~L}^{-1}$ ) and $\mathrm{NaOH}$ (analytical reagent grade, $0.1 \mathrm{~mol} \mathrm{~L}^{-1}$ ) were used to adjust the initial $\mathrm{pH}$ of DMP solution. The terephthalic acid (chromatographic reagent grade) purchased from Shanghai Chemical Reagent Company of China was used as a capture agent for hydroxyl radical detection using fluorescence technology. Distilled water was used for preparing DMP solution in this experiment.

\section{Methods}

For the MW/PC and the MW processes, a SANYO 800 domestic microwave oven (frequency, $2.45 \mathrm{GHz}$; maximal power, $700 \mathrm{~W}$ ) modified by Sichuan University was used as the microwave source. The pulse of the microwave oven was continuous and the power was adjustable. The UV source for the MW/PC process was a MDEL (length, $100 \mathrm{~mm}$; diameter, $25 \mathrm{~mm}$; filled with mercury and argon) manufactured by Shanghai Jiguang Special Illumination Instrument Factory. The MDEL showed maximal emission at $254 \mathrm{~nm}$, and the UV light intensity determined by a radiometer (Photoelectric Instrument Factory of Beijing Normal University) increased linearly with the microwave power (equation 1),

$y=0.0162 x+3.5584, \quad \mathrm{R}^{2}=0.9617$

where $y=\mathrm{UV}$ light intensity $\left(\mathrm{mW} \mathrm{cm}^{-2}\right)$ and $x=$ microwave power (W).

In the MW/PC process, a glass reactor (height $=$ $1200 \mathrm{~mm}$, diameter $=50 \mathrm{~mm}$ ) was put into the microwave oven and the MDEL was vertically fixed in the groove on the center of the bottom of the glass reactor. A water reflux condenser was inserted in the top hole of the reactor through the hole on the microwave oven to condense the vapor from the reactor. The temperature was measured by a thermocouple through the side-hole on the reactor. The schematic illustration of the microwave-assisted photoreactor was shown in Figure 1.

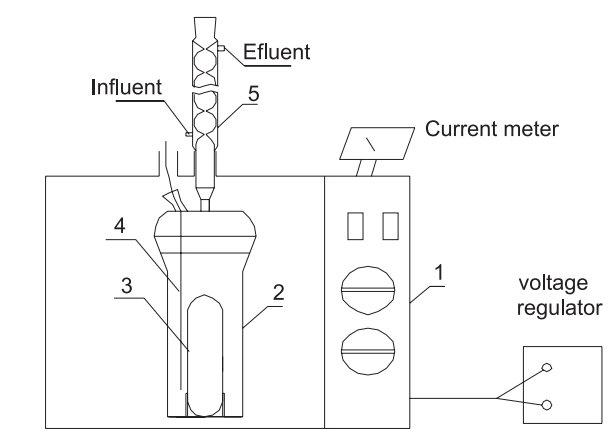

1-modified domestic microwave oven; 2-glass photoreactor; 3-microwave discharged electrodeless lamp; 4-thermal couple; 5 -water reflux condenser

Figure 1. Schematic illustration of the microwave-assisted photoreactor.

For the PC, the TH/PC and the photolysis processes, a Heraeus GU22-10T5L Hg lamp (15 W; maximum emission at $254 \mathrm{~nm}$; light intensity, $12.61 \mathrm{~mW} \mathrm{~cm}-2$ ) was used as the UV source. An electric heating-jacket was involved in the $\mathrm{TH} / \mathrm{PC}$ process as an external thermal source, and also a water reflux condenser was inserted in the reactor to condense the vapor from the reactor.

During all the experiments unless especially noted, a $100 \mathrm{~mL}$ DMP solution (10 mg L-1, $\mathrm{pH}$ 5.6) with $1.0 \mathrm{~g} \mathrm{~L}^{-1}$ $\mathrm{TiO}_{2}$ was added into the reactor and stirred in the dark for $30 \mathrm{~min}$ for adsorption-desorption equilibrium before 
reactions, and for the MW/PC process, the microwave power was $400 \mathrm{~W}$ (MDEL light intensity $=9.79 \mathrm{~mW} \mathrm{~cm}^{-2}$ ), the reaction time was $30 \mathrm{~min}$. In addition, the MW and the photolysis processes were carried out without $\mathrm{TiO}_{2}$; the $\mathrm{PC}$ and the photolysis processes were conducted under $20{ }^{\circ} \mathrm{C}$; the MW/PC, the $\mathrm{MW}$ and the $\mathrm{TH} / \mathrm{PC}$ processes were carried out at $130 \pm 2{ }^{\circ} \mathrm{C}$ by the heat from the microwave oven or the electric heating jacket. The experiments in this study were all performed in duplicate, and the error bars of these experiments were $\pm 5 \%$.

\section{Analytical methods}

Samples taken at different time intervals were immediately filtered through a Millipore $(0.45 \mu \mathrm{m})$ membrane using a syringe prior to the analysis. The UV absorption of DMP was determined with a Shimadzu UV-2550 spectrophotometer and the removal efficiency of DMP was assayed by the decrease of UV absorption at the maximum characteristic absorption wavelength of DMP at $230 \mathrm{~nm}$. The relation between UV absorption at $230 \mathrm{~nm}$ and DMP concentration is shown in equation 2:

$A=0.0397 c-0.0083, \quad \mathrm{R}^{2}=0.9987$

The decrease in total organic carbon (TOC) was determined with a Shimadzu TOC $5000 \mathrm{~A}$. The intermediates produced from the degradation of DMP were identified using a Finnigan LCQ DECA XP MAX LC-MSD apparatus (liquid chromatograph coupled to an electrospray mass spectra detector operated in the negative and positive modes), and the eluent was a mixed solution of methanol and water $(1: 1, \mathrm{v} / \mathrm{v})$.

The determination of hydroxyl radicals was conducted by a fluorescence method proposed by Ken-ichi Ishibashi et al. ${ }^{16}$ In this method, the capture agent terephthalic acid reacts with hydroxyl radicals to form the only highly fluorescent hydroxy product 2-hydroxyterephthalic acid. The hydroxy product has fluorescence emission peak at $425 \mathrm{~nm}$ under the excitation wavelength at $315 \mathrm{~nm}$. Analysis of the resultant hydroxy compound provides sensitive and specific monitoring of the generated hydroxyl radicals. For terephthalic acid, in order to ensure solubility, solution was prepared in dilute $\mathrm{NaOH}$ solution $\left(0.1 \mathrm{~mol} \mathrm{~L}^{-1}\right)$. Fluorescence spectra of the generated 2-hydroxyterephthalic acid were measured with a JASCO FP-6500 fluorescence spectrophotometer. The excitation wavelength was $315 \mathrm{~nm}$ and the scanning range was $250-600 \mathrm{~nm}$. The initial concentration of the terephthalic acid was $800 \mathrm{mg} \mathrm{L}^{-1}$, which could ensure all the hydroxyl radicals being trapped by capture agent under experimental condition.

\section{Results and Discussion}

\section{Effect of catalyst dosage}

Degussa P-25 $\mathrm{TiO}_{2}$ was used as the photocatalyst in this study. Under the experimental $\mathrm{TiO}_{2}$ dosage from 0.5 to $3 \mathrm{~g} \mathrm{~L}^{-1}$, the change of catalyst dosage did not have much effect on the DMP removal efficiency and the removal efficiencies kept at high level in the whole experimental dosage range.

\section{Effect of $p H$}

The initial $\mathrm{pH}$ of the unadjusted DMP solution was 5.6. Aqueous $\mathrm{HCl}\left(0.1 \mathrm{~mol} \mathrm{~L}^{-1}\right)$ and $\mathrm{NaOH}\left(0.1 \mathrm{~mol} \mathrm{~L}^{-1}\right)$ were used to adjust the initial $\mathrm{pH}$ to 3, 5, 7, 9 and 11 . The degradation of DMP solution was enhanced in an acid medium but weakened in an alkaline medium. The increased removal efficiency in the acid medium could be attributed to the enhanced production of hydroxyl radicals. Specifically, more $\mathrm{H}^{+}$in the solution, more conduction band electrons could transfer to the surface of the catalyst and react with $\mathrm{O}_{2}$ to produce more hydroxyl radicals. In contrast, the alkaline medium might cause a reduction of hydroxyl radical concentration, according to Muruganandham and Swaminathan. ${ }^{17}$

\section{Effect of DMP concentration}

The variation of the DMP removal efficiencies under different initial DMP concentrations, ranging from 5 to $80 \mathrm{mg} \mathrm{L}^{-1}$, was investigated. The removal efficiency decreased when the initial DMP concentration increased, which might be due to the intermediates produced in the DMP degradation process competing with the initial DMP pollutants for the adsorption site on the surface of the $\mathrm{TiO}_{2}$ catalysts. Besides, the rise in the DMP concentration induced an inner filter effect on light. Consequently, the solution became more and more impermeable to microwave and UV radiation, and lowered hydroxyl radical concentration, according to Behnajady et al. ${ }^{18}$

\section{Effect of UV light intensity}

In this experiment, the light intensity of the MDEL could be changed by adjusting the microwave power, and the light intensity emitted from the MDEL increased linearly with the microwave power (as shown in equation 1). Increasing the UV light intensity could enhance DMP removal efficiencies, which was in accordance with the results from Kim et al. ${ }^{19}$ The enhanced removal efficiencies might be 
because the higher light intensity could give more light energy for the breaking of chemical bonds of DMP, and the reactions between the light and the catalysts could improve the formation of hydroxyl radicals in the solution.

\section{Effect of irradiation time}

The removal efficiencies of UV absorption at $230 \mathrm{~nm}$ and total organic carbon (TOC) of DMP by MW/PC process for different irradiation time intervals were investigated (Figure 2). DMP could be rapidly and completely degraded by the MW/PC process. Particularly, the UV absorption removal efficiency was about $80 \%$ within the first $10 \mathrm{~min}$. Prolonging the irradiation time could result in enhanced UV absorbance and TOC removal efficiencies.

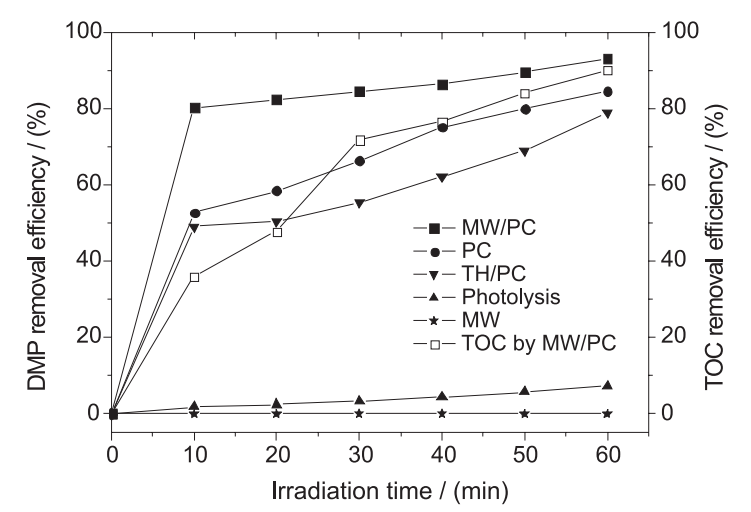

Figure 2. Comparison of the degradation of DMP by different processes. $\mathrm{C}_{\mathrm{ODMP}}=10.22 \mathrm{mg} \mathrm{L}^{-1}, \mathrm{TOC}_{0}=20.82 \mathrm{mg} \mathrm{L}^{-1}$, solution volume $=100 \mathrm{~mL}$, $\mathrm{C}_{\mathrm{TiO} 2}=1.0 \mathrm{~g} \mathrm{~L}^{-1}$, microwave power $=400 \mathrm{~W}$, MDEL light intensity $=$ $9.79 \mathrm{~mW} \mathrm{~cm}^{-2}$, Hg lamp light intensity $=12.61 \mathrm{~mW} \mathrm{~cm}^{-2}$. The MW and the photolysis processes were carried out without $\mathrm{TiO}_{2}$ catalysts. The temperatures for MW/PC, TH/PC and MW processes were $135^{\circ} \mathrm{C}$, while the temperatures for PC and photolysis processes were both $20{ }^{\circ} \mathrm{C}$.

\section{Synergistic effects in the MW/PC process}

The removal efficiencies of DMP in MW/PC, PC, $\mathrm{TH} / \mathrm{PC}, \mathrm{MW}$ and photolysis processes were reported (Figure 2). It was obvious that MW irradiation alone was almost ineffective to degradation of DMP even after irradiation of $60 \mathrm{~min}$. Photolysis had slight efficiency on decomposition of DMP and the slight decomposition might be attributed to the break-up of bonds of DMP compounds by the energy of UV light around $254 \mathrm{~nm}$.

Results also showed that the MW/PC process was much superior to the $\mathrm{PC}$ and the TH/PC processes on the degradation of DMP, especially for the first $10 \mathrm{~min}$. After irradiation of $10 \mathrm{~min}$, the removal efficiency of DMP in MW/PC process reached $80.3 \%$, while only $52.72 \%$ in PC process and $49.01 \%$ in TH/PC process. The DMP removal efficiency in MW/PC was superior to the sum of those in PC and MW processes. It could be concluded that microwave irradiation could greatly accelerate the photocatalytic process, and significant synergistic effects existed between microwave irradiation and $\mathrm{TiO}_{2}$ photocatalysis.

Furthermore, it could be found that the heat from the electric heating-jacket could not enhance the removal efficiency of DMP in PC process, whereas irradiation of microwave greatly enhanced DMP degradation efficiency in $\mathrm{PC}$ process, even though temperature of the dispersion in TH/PC process was identical with that in MW/PC process. Therefore, it could be inferred that the heat from the microwave irradiation was not the main factor causing higher removal efficiency in MW/PC process, but higher removal efficiency was likely related to non-thermal effects from microwave irradiation. Microwave irradiation might improve charge carrier to the surface leading to increase formation of surface hydroxyl radicals. In addition, microwave irradiation likely generated additional defect sites on the $\mathrm{TiO}_{2}$ particles, which inhabited electron/hole recombination and resulted in an enhanced photocatalytic process. $^{20}$

\section{Formation of hydroxyl radicals}

The relative fluorescence intensities of the generated 2-hydroxyterephthalic acid at $425 \mathrm{~nm}$, in different degradation processes after irradiation of $10 \mathrm{~min}$, were compared (Figure 3). It was evident that formation of hydroxyl radicals by MW/PC process was much superior to that by PC and TH/PC processes. Direct photolysis and direct microwave irradiation in absence of $\mathrm{TiO}_{2}$ had little impact on the formation of hydroxyl radicals. The UV-illuminated $\mathrm{TiO}_{2}$ surface had a comparatively large contribution to the formation of hydroxyl radicals. The addition of thermal heating jacket did not improve hydroxyl radical's formation, comparing the result of PC process with that of TH/PC process. It could be also confirmed that synergistic effects between microwave irradiation and UV-illuminated $\mathrm{TiO}_{2}$ surface could give rise to the generation of hydroxyl radicals which caused rapid degradation of DMP in MW/PC process.

The relative fluorescence intensities $\left(\lambda_{\mathrm{em}}=425 \mathrm{~nm}\right)$ of 2-hydroxyterephthalic acid formed in MW/PC process after different irradiation times were also studied (Figure 4). Obviously, the relative fluorescence intensity increased with the prolonged irradiation time. Since the relative fluorescence intensity of the produced 2-hydroxyterephthalic acid increased linearly with the concentration of hydroxyl radicals, the concentration of hydroxyl radicals produced in the MW/PC process increased when the irradiation time was prolonged. Moreover, the concentration of hydroxyl radicals was one of the important factors for 


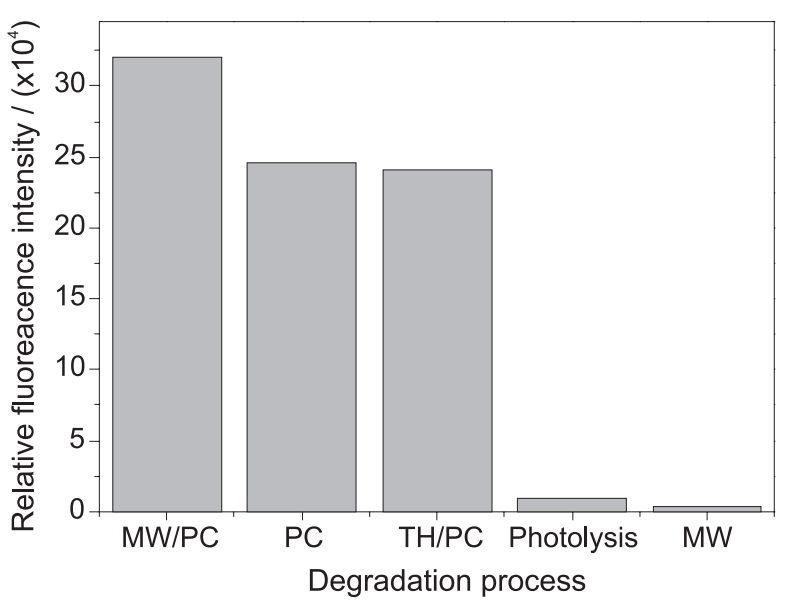

Figure 3. Comparison of the hydroxyl radicals formed in different processes. Terephthalic acid solution volume $=100 \mathrm{~mL}, \mathrm{C}_{0}=800 \mathrm{mg} \mathrm{L}^{-1}$, $\lambda_{\mathrm{ex}}=315 \mathrm{~nm}, \lambda_{\mathrm{em}}=425 \mathrm{~nm}$.

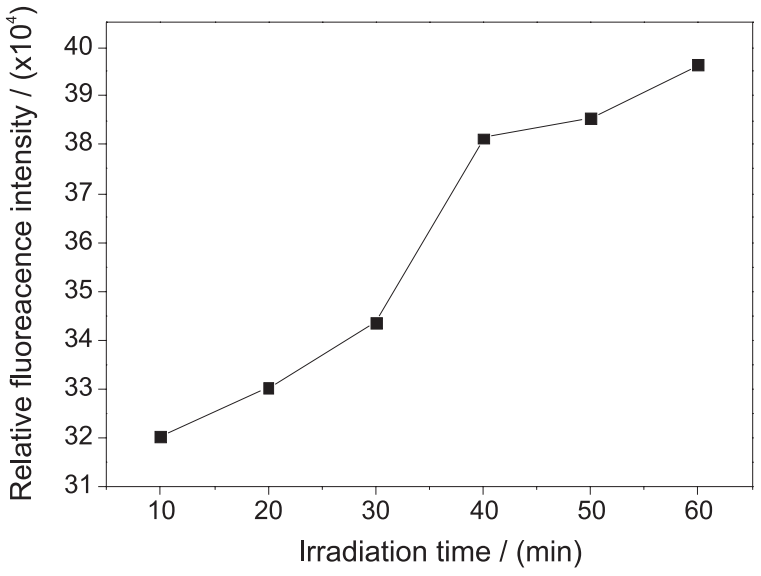

Figure 4. Effect of irradiation time on the relative fluorescence intensity of 2-hydroxyterephthalic acid in MW/PC process. Terephthalic acid solution volume $=100 \mathrm{~mL}, \mathrm{C}_{0}=800 \mathrm{mg} \mathrm{L}^{-1}, \mathrm{C}_{\mathrm{TiO} 2}=1.0 \mathrm{~g} \mathrm{~L}^{-1}$, microwave power $=$ $400 \mathrm{~W}, \mathrm{UV}$ light intensity $=9.79 \mathrm{~mW} \mathrm{~cm}^{-2}, \lambda_{\mathrm{ex}}=315 \mathrm{~nm}, \lambda_{\mathrm{em}}=425 \mathrm{~nm}$.

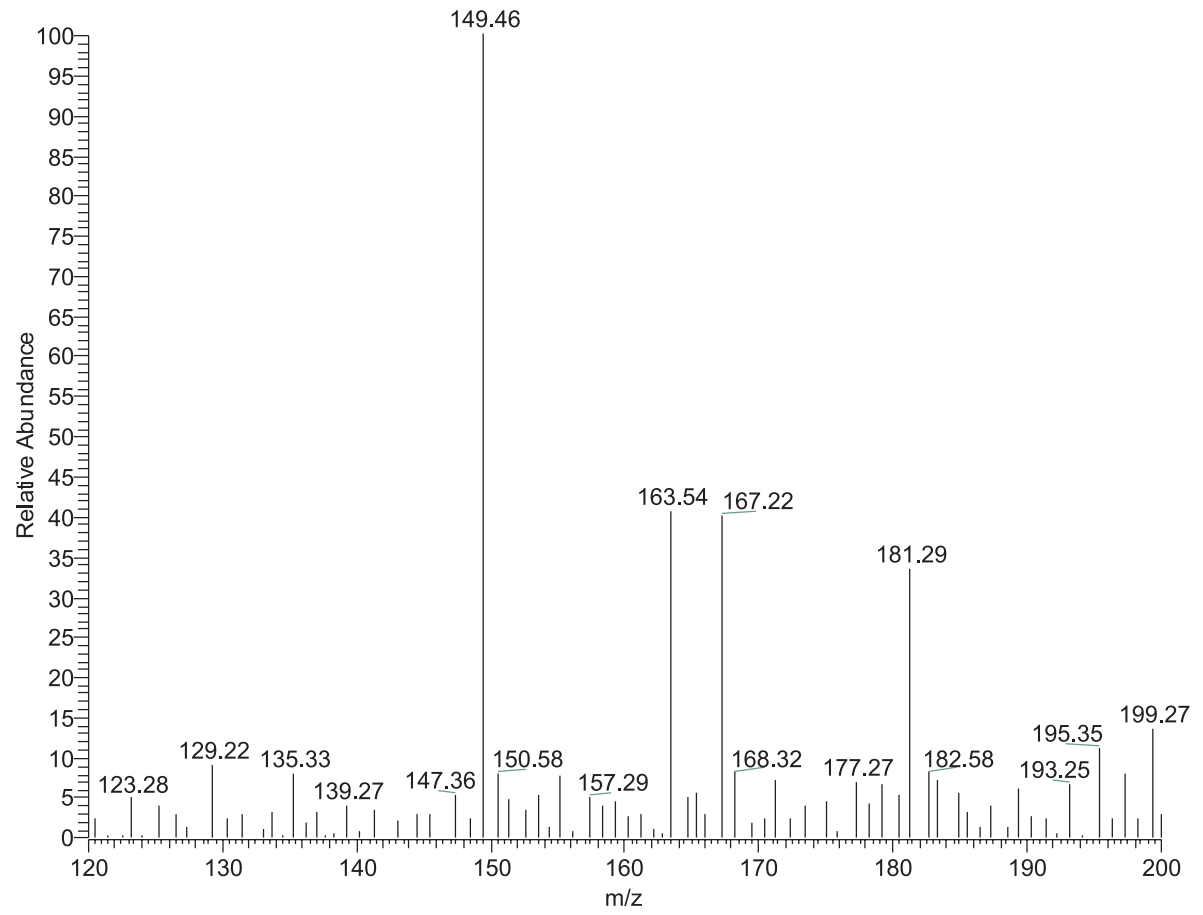

Figure 5. Electrospray mass spectra in the positive mode recorded during MW/PC process after 10 min irradiation.

effective photodegradation of organic pollutants using $\mathrm{TiO}_{2}$ photocatalysts, as a consequence, the degradation of DMP was more complete after a longer irradiation time (as illustrated in Figure 2).

\section{Identification of intermediates and mechanistic analysis}

The identification of intermediates formed in the degradation process of DMP by MW/PC process was carried out with LC-MS technique. The intermediates formed after irradiation of 10 min by MW/PC process were identified from positive modes (Figure 5). The signal at $\mathrm{m} / \mathrm{z}=195.35$ which might belong to DMP has been strongly weakened after $10 \mathrm{~min}$ of irradiation and four major intermediates were formed according to the signals in the mass spectra. The signal at $\mathrm{m} / \mathrm{z}=181.10$ might belong to phthalic acid monomethyl ester. The signal at $m / z=167.07$ might be phthalic acid. The signal at $m / z=163.43$ was expected to be $o$-phenyl diethyl ketone, and the signal at $\mathrm{m} / \mathrm{z}=149.41 \mathrm{might}$ belong to $o$-phthalic anhydride.

The UV absorption spectra of the DMP before and after irradiation of $40 \mathrm{~min}$ by MW/PC process were 
also presented (Figure 6). The UV spectrum of DMP comprises two maxima, a weak peak at $280 \mathrm{~nm}$ and a strong peak at $230 \mathrm{~nm}$. After $40 \mathrm{~min}$ of irradiation by MW/PC process, the absorption spectra of DMP almost disappeared. It was believed that the aromatic ring of DMP had been destroyed by MW/PC process. It also indicated that the intermediates formed after irradiation of $10 \mathrm{~min}$ had been degraded into small molecules by further irradiation.

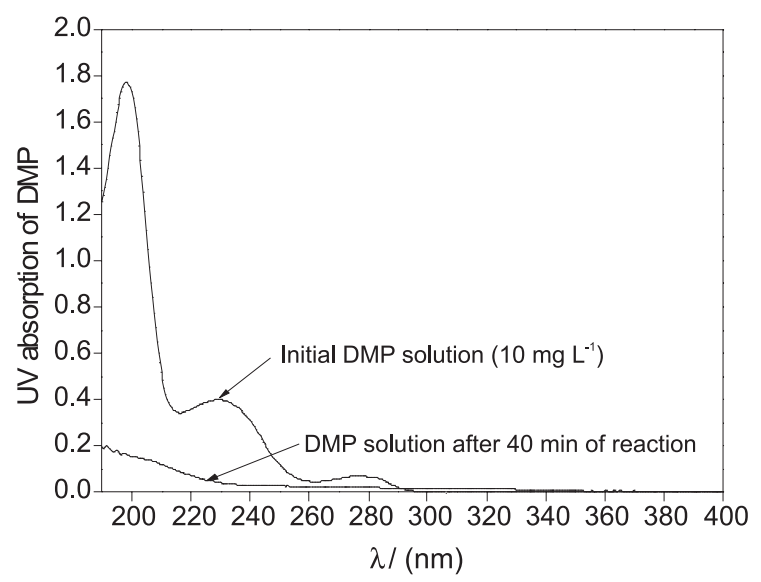

Figure 6. UV absorption spectra of the DMP before and after $40 \mathrm{~min}$ irradiation by $\mathrm{MW} / \mathrm{PC}$ process. $\mathrm{C}_{0 \mathrm{DMP}}=10.22 \mathrm{mg} \mathrm{L}^{-1}$, solution volume $=100 \mathrm{~mL}, \mathrm{C}_{\mathrm{TiO} 2}=1.0 \mathrm{~g} \mathrm{~L}^{-1}$, microwave power $=400 \mathrm{~W}, \mathrm{MDEL}$ light intensity $=9.79 \mathrm{~mW} \mathrm{~cm}^{-2}$.

On the basis of the above results and discussion, we proposed the initial mechanistic steps for degradation of DMP by MW/PC process (Figure 7). For MW/PC system, the major intermediates were all formed by the attack of hydroxyl radicals on the alkyl chains of DMP, and due to different attacking positions, different intermediates were produced. In addition, lifetime of the intermediates was short, and the intermediates would be destroyed into small species by further irradiation in MW/PC process.

\section{Conclusions}

An alternative method for the degradation of DMP was proposed. The best removal efficiency of MW/PC process was obtained when the $\mathrm{TiO}_{2}$ dosage was $1.0 \mathrm{~g} \mathrm{~L}^{-1}$, the initial $\mathrm{pH}$ of DMP was 5, the initial concentration of DMP was $5 \mathrm{mg} \mathrm{L}^{-1}$, the UV light intensity was $14.08 \mathrm{~mW} \mathrm{~cm}^{-2}$ and the irradiation time was $60 \mathrm{~min}$. Under these conditions, it was possible to reach $100 \%$ of DMP removal monitored by UV absorption and TOC. The MW/PC process has shown rapid and complete degradation compared to alternative oxidation process. Synergistic effects were found to exist between microwave irradiation and $\mathrm{TiO}_{2}$ photocatalysis, and the greater efficiency of MW/PC process might be ascribed to non-thermal effects of microwave irradiation. The hydroxyl radical detection results confirmed that microwave irradiation could give rise to the generation of hydroxyl radicals. The major intermediates of DMP in the MW/PC process were phthalic acid monomethyl ester, phthalic acid, $o$-phenyl diethyl ketone and $o$-phthalic anhydride. MW/PC technique can potentially be applied for the pretreatment of hardly biodegradable organic wastewater before bio-treatment.

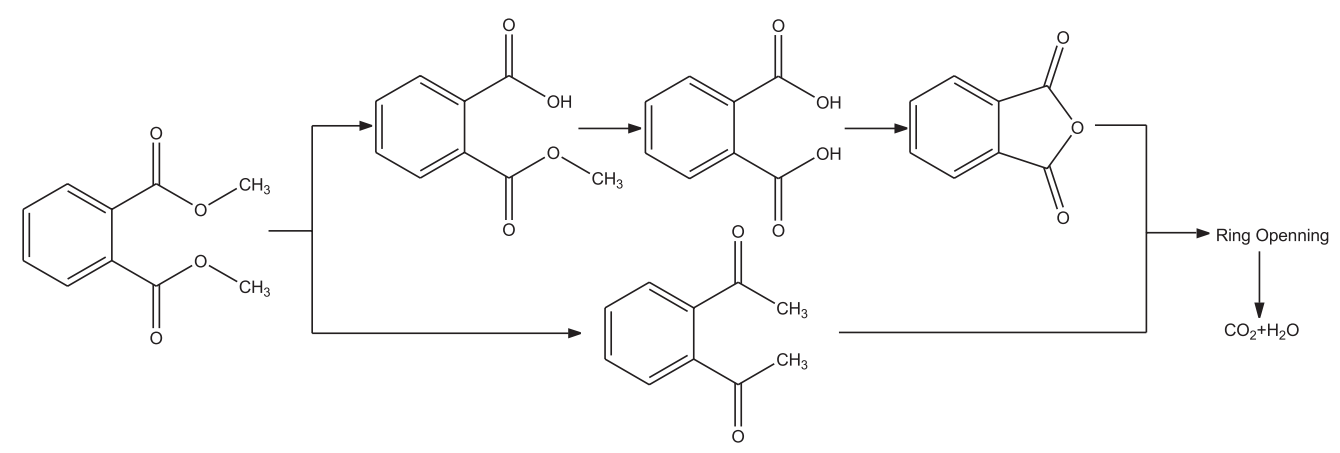

Figure 7. Proposed initial degradation mechanism of DMP by MW/PC process.

\section{Acknowledgement}

The authors acknowledge the financial support from National Nature Science Foundation of China (No. 50678045).

\section{References}

1. Allsopp, M.; Santillo, D.; Johnston, P.; Poisoning the Future: Impacts of Endocrine-Disrupting Chemicals on Wildlife and Human Health, Greenpeace International: The Netherlands, 1997. 
2. Marttinena, S.K.; Kettunenb, R.H.; Sormunena, K.M.; Rintala, J.A.; Water Res. 2003, 37, 1385.

3. Roslev, P.; Vorkamp, K.; Aarup, J.; Frederiksen, K.; Nielsen, P.H.; Water Res. 2007, 41, 969.

4. Wang, J.; Liu, P.; Shi, H.; Qian, Y.; Chemosphere 1998, 37, 257.

5. Adhoum, N.; Monser, L.; Sep. Purif. Technol. 2004, 38, 233.

6. Ejlertsson, J.; Alnervik, M.; Jonsson, S.; Svesson, B.H.; Environ. Sci. Technol. 1997, 31, 2761.

7. Taborda, A.V.; Brusa, M.A.; Grela, M.A.; Appl. Catal., A. 2001, 208, 419.

8. Rahman, M.A.; Muneer, M.; Bahnemann, D.; Res. Chem. Intermed. 2003, 29, 35.

9. Zhang, G.Y.; Wang, P.; Shi, Y.; Ma, H.J.; Hong, G.; Chin. J. Catal. 2005, 26, 597.

10. Bi, X.Y.; Wang, P.; Jiang, H.; Xu, H.Y.; Shi, S.J.; Huang, J.L.; J. Environ. Sci. 2007, 19, 1510.

11. Bi, X.Y.; Wang, P.; Jiang, H.; J. Hazard Mater. 2008, 154, 543.
12. Horikoshi, S.; Hidaka, H.; Serpone, N.; Environ. Sci. Technol. 2002, 36, 1357.

13. Horikoshi, S.; Hojo, F.; Hidaka, H.; Environ. Sci. Technol. 2004, 38,2198 .

14. Horikoshi, S.; Hidaka, H.; Serpone, N.; J. Photochem. Photobiol., A 2003, 159, 289.

15. Zhang, X.W.; Li, G.T.; Wang, Y.Z.; Dyes Pigm. 2007, 74, 536.

16. Ishibashi, K.I.; Fujishima, A.; Watanabe, T.; Hashimoto, K.; Electrochemistry Commun. 2000, 2, 207.

17. Muruganandham, M.; Swaminathan, M.; Dyes Pigm. 2004, 62, 269.

18. Behnajady, M.A.; Modirshahla, N.; Shokri, M.; Chemosphere 2004, 55, 129.

19. Kim, S.B.; Hong, S.C.; Appl. Catal., B 2002, 35, 305.

20. Horikoshi, S.; Hidaka, H.; Serpone, N.; J. Photochem. Photobiol., A 2002, 153, 185.

Received: September 25, 2008 Web Release Date: March 27, 2009 